\title{
LONG-TERM FOLLOW-UP OF CERVICAL SPONDYLOTIC MYELOPATHY TREATED BY CANAL-EXPANSIVE LAMINOPLASTY
}

ISAO KIMURA, HIKOSUKE SHINGU, YOSHIRO NASU, ET AL

From San-in Rosai Hospital, Tottori, Japan

We have studied 29 patients for at least five years after canal-expansive laminoplasty for cervical spondylotic myelopathy. The short- and long-term clinical results were compared, and successive radiographs assessed.

The long-term clinical outcome was excellent in five patients, good in 12, fair in 11 and poor in one. The mean short- and long-term improvements were $54.4 \%$ and $48.5 \%$ but patients with focal kyphotic, kyphotic and S-shaped cervical spines did less well, as did those who had a decrease in the index of curvature of the cervical spine of more than $\mathbf{1 0}$ at follow-up.

Canal-expansive laminoplasty with reconstitution of the posterior soft tissues may help to prevent postoperative malalignment and late neurological deterioration.

J Bone Joint Surg [Br] 1995;77-B:956-61. Received 20 February 1995; Accepted 20 April 1995

Degenerative changes in the cervical spine or ossification of the posterior longitudinal ligament (OPLL) lead to increased narrowing of the spinal canal. Decompression by laminectomy has been the conventional treatment for severe narrowing of the spinal canal, but extensive resection of the posterior components of the spine may lead to instability with recurrence of symptoms (Crandall and Gregorius 1977).

Recently, operations for spinal canal laminoplasty have been introduced which are osteoplastic, provide good decompression and prevent constriction of the spinal cord due to postoperative adhesions (Oyama et al 1973; Hir-

I. Kimura, MD, Orthopaedic Surgeon

H. Shingu, MD, Director

Y. Nasu, MD, Orthopaedic Surgeon

A. Shiotani, MD, Orthopaedic Surgeon

M. Oh-hama, MD, Orthopaedic Surgeon

M. Murata, MD, Orthopaedic Surgeon

Department of Orthopaedic Surgery, San-in Rosai Hospital, 1-8-1 Kaikeshinden, Yonago, Tottori 683, Japan.

Correspondence should be sent to Dr I. Kimura.

(01995 British Editorial Society of Bone and Joint Surgery 0301-620X/95/61081 $\$ 2.00$ abayashi et al 1981; Tsuji 1982; Itoh and Tsuji 1985; Kurokawa, Nakamura and Machida 1986). We have used this procedure in cervical spondylotic myelopathy and OPLL of the cervical spine, and have described the integrity of the expanded vertebral arches after two years as assessed by CT (Kimura, Oh-Hama and Shingu 1984).

In this study we compared the short- and long-term clinical results and serially reviewed the radiographs to clarify the long-term outcome of the operation, considering particularly the neurological changes.

\section{PATIENTS AND METHODS}

Of 37 patients followed up for at least five years, 29 were available for examination. There were 15 men and 14 women. Their mean age at operation was 63 years (51 to 78) and the duration of follow-up was 7.1 years (5 to 14). As judged by the classification of Crandall and Gregorious (1977), the neurological findings before operation were a transverse syndrome in 21 , a central syndrome in five and brachialgia in 3 . The mean interval from the onset of symptoms to operation was 1 year 11 months.

Assessment of results. We graded the severity of the clinical picture and the quality of the results using the scoring system of the Japanese Orthopaedic Association (1994). From a total of 17 points, a maximum of four points each is deducted for a motor deficit in the lower limb and one in the upper limb; a maximum of three points each is deducted for a sensory deficit in the lower limb, one in the upper limb, and one in the trunk; and a maximum of three points is deducted for urinary disturbance. An excellent result was $80 \%$ to $100 \%$ of a perfect score of 17 points; good $60 \%$ to $79 \%$ (usually 14 points or more), fair $20 \%$ to $59 \%$ (usually 13 points or less), and poor $19 \%$ or less.

Radiological evaluation. Changes in alignment after operation were examined on lateral radiographs of the cervical spine in the intermediate position and were classified as lordotic, straight, focal kyphotic, kyphotic, Sshaped, and inverted S-shaped types. Degenerative slip was diagnosed if there was a shift of $2 \mathrm{~mm}$ or more.

The index of curvature of the cervical spine (CCI) was calculated by the Ishihara method (Fig. 1). The 29 patients were classified as follows: group I were those with a decrease in the CCI of less than 9 at follow-up and group II were those with a decrease of more than 10. Group-A 


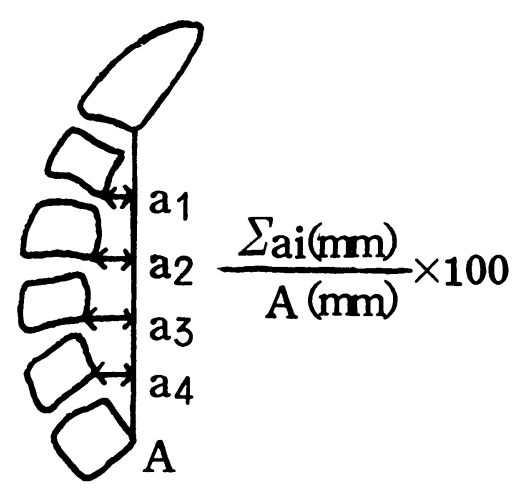

Fig. 1

Calculation of the cervical spinal curvature index (CCI) by the method of Ishihara (1968).

patients had a lordotic or straight spine before operation and retained this alignment, and group B patients had other types of alignment at follow-up.

Of the 29 patients 15 were group I-A, 10 group I-B and 4 group II-B. The mean age at operation was 63.4 years in group I-A, 62.8 years in group I-B and 60.0 years in group II-B.

Operative technique. Patients with stenosis which included several segments had a canal-expansive laminoplasty of the involved level using a technique based on that of Hirabayashi et al (1981). Decompression was made en bloc by dividing the cephalic and caudal ligamenta flava to allow lifting of the flap (Kimura et al 1984). Four to six vertebral laminae (mean 4.3) were expanded as a single flap. Posterolateral fusion was performed simultaneously at one level in three patients and at two levels in one.

The patients remained on bedrest for two weeks and then began using a fronto-occipital zygomatic brace. Isometric exercises wearing the brace were started three weeks after operation.

\section{RESULTS}

Clinical scores and percentage improvement. The mean preoperative score of the 15 patients in group I-A was 8.4 points (3 to 14). The mean score after operation in the short term (6 to 12 months) and long term (5 to 14 years) was 13.4 and 13.6 points, respectively. In group I-B, the mean preoperative score was 10.1 points (4 to 14) and at shortterm and long-term review was 13.8 and 13.4 points, respectively. In group II-B, the mean preoperative score was 9.3 points (5 to 15 ) and at short-term and long-term follow-up was 13.5 and 12.0 points, respectively.

The mean short-term and long-term improvements were $56.9 \%$ and $60.4 \%$, respectively, in group $\mathrm{I}-\mathrm{A}, 53.6 \%$ and $47.8 \%$ in group I-B, and $54.5 \%$ and $35.6 \%$ in group II-B (Table I). These improvements remained unchanged over a long period in group I-A and group I-B, but in group II-B the original improvement began to deteriorate in the long term.

Clinical results. The clinical long-term result in group I-A and I-B was excellent in 5 patients, good in 12 and fair in 8. In group II-B it was fair in three patients and poor in one (Table II).

Table I. The mean ( \pm SD) clinical scores and percentage improvement in 29 patients who had canal-expansive laminoplasty

\begin{tabular}{|c|c|c|c|c|c|}
\hline & \multicolumn{3}{|c|}{ Clinical scores (points) } & \multirow{2}{*}{\multicolumn{2}{|c|}{ Postop improvement (\%) }} \\
\hline & \multirow[b]{2}{*}{ Preop } & \multicolumn{2}{|l|}{ Postop } & & \\
\hline & & Short-term & Long-term & Short-term & Long-term \\
\hline Group I-A & $8.4 \pm 3.2^{*}$ & $13.4 \pm 1.8 *$ & $13.6 \pm 1.9^{*}$ & $56.9 \pm 18.2$ & $60.4 \pm 21.0$ \\
\hline Group I-B & $10.1 \pm 2.3^{*}$ & $13.8 \pm 2.1^{*}$ & $13.4 \pm 2.8^{*}$ & $53.6 \pm 19.8$ & $47.8 \pm 20.4$ \\
\hline Group II-B & $9.3 \pm 3.6^{*}$ & $13.5 \pm 1.2 *$ & $12.0 \pm 2.7^{*}$ & $54.5 \pm 7.6$ & $35.6 \pm 11.7$ \\
\hline All & $9.3 \pm 3.5^{*}$ & $13.5 \pm 1.9^{*}$ & $13.0 \pm 2.4^{*}$ & $54.5 \pm 17.9$ & $48.5 \pm 22.8$ \\
\hline
\end{tabular}

* $\mathrm{p}<0.01$ between preoperative and postoperative scores

Table II. The clinical short-term and long-term results in the three groups

\begin{tabular}{llrll}
\hline & Excellent & Good & Fair & Poor \\
\hline Group I-A $(\mathrm{n}=15)$ & & & & \\
$\quad$ Short-term & 2 & 10 & 3 & \\
Long-term & 4 & 8 & 3 & \\
Group I-B $(\mathrm{n}=10)$ & & & & \\
$\quad$ Short-term & 1 & 5 & 4 & \\
Long-term & 1 & 4 & 5 & \\
Group II-B $(\mathrm{n}=4)$ & & & & \\
$\quad$ Short-term & & 2 & 2 & \\
Long-term & & & 3 & 1 \\
\hline
\end{tabular}

\section{Radiological evaluation}

Range of motion (ROM) of the cervical spine. The ROM of the cervical spine was measured by the Nishituzi (1963) method on lateral radiographs in maximum flexion and extension, and the percentage change in the ROM after operation was assessed. The mean ROM was reduced from a preoperative value of $40.7^{\circ}$ to $25.4^{\circ}$ at follow-up, a decrease of $62 \%$ (Table III).

Cervical spine curvature index (CCI). In group I-A the mean CCI decreased from 16.4 before operation to 7.6 at follow-up, indicating a decrease in lordosis. In group I-B, it 


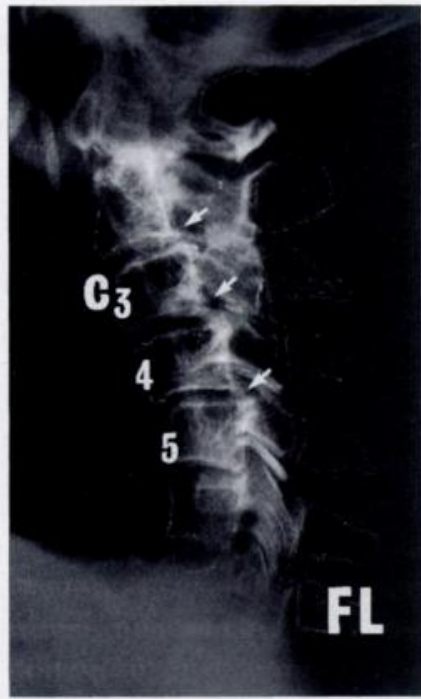

Fig. 2a

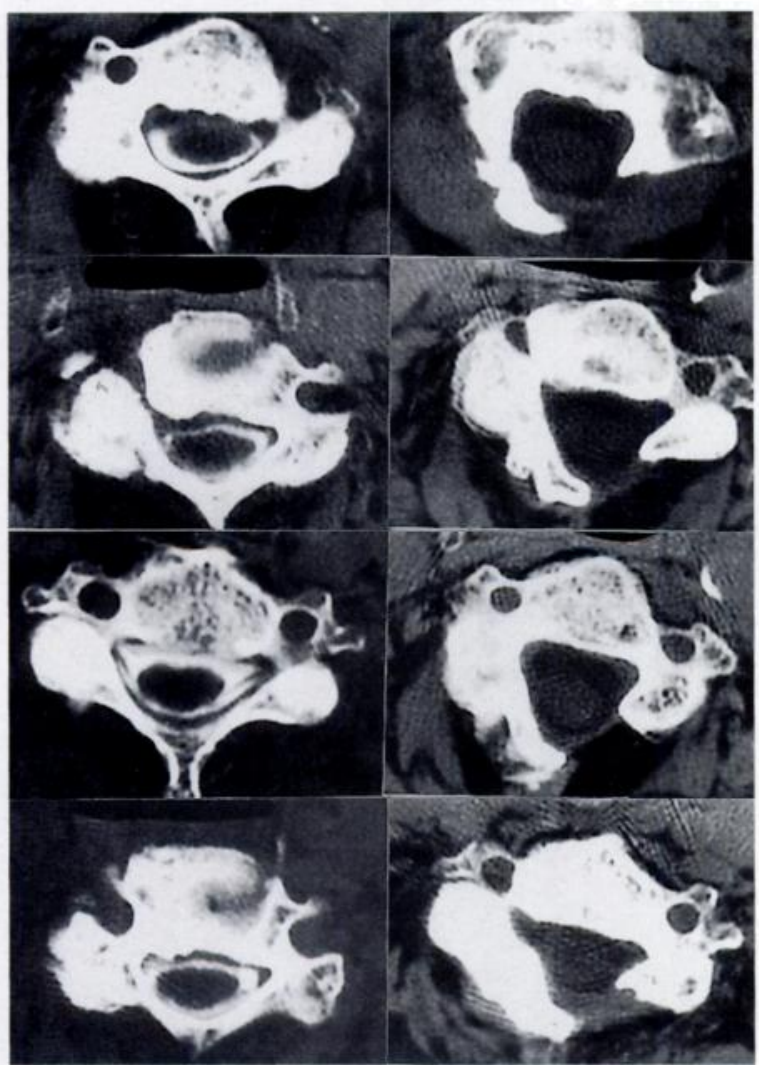

Fig. 2e

decreased from -0.7 to -2.0 and the decrease in lordosis or slight kyphosis was more notable. In group II-B the decrease was from -4.7 to -18.0 , indicating an increase in kyphosis (Table III).

Alignment of the cervical spine. In group I-B the three patients with a straight spine changed to the focal kyphotic type and one of the six patients with the focal kyphotic type progressed to the kyphotic type. Deterioration of alignment

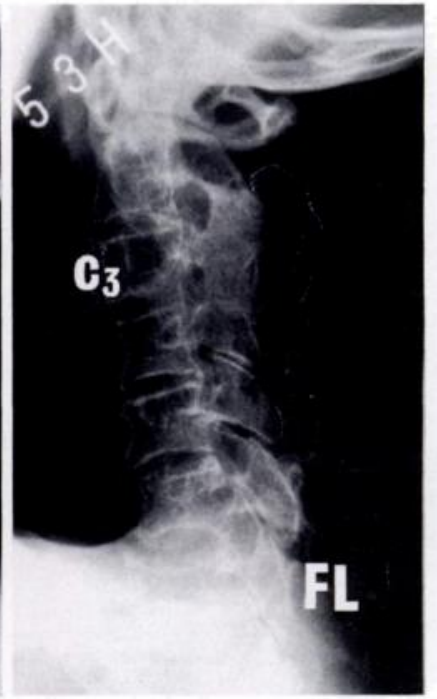

Fig. 2c

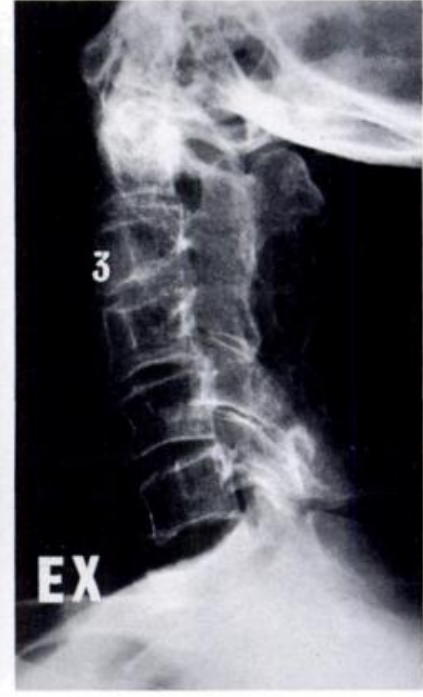

Fig. 2d
Figures 2a,b - A 70-year old woman with a spastic gait, urinary disturbance and numbness in the arm, showed a straight cervical spondylosis with slips at $\mathrm{C} 2 / \mathrm{C} 3, \mathrm{C} 3 / \mathrm{C} 4$ and $\mathrm{C} 4 / \mathrm{C} 5$. After canal-expansive laminoplasty between $\mathrm{C} 2$ and $\mathrm{C} 5$, and posterolateral fusion at $\mathrm{C} 2 / \mathrm{C} 3$ and $\mathrm{C} 3 / \mathrm{C} 4$, her clinical score had increased from 8 points to 14 . Figures $2 \mathrm{c}, \mathrm{d}-$ Five years later, it had improved to 15 , with a straight cervical spondylosis and a stable cervical spine. Figure $2 \mathrm{e}-\mathrm{CT}$ changes at seven years (right). The canal lies open with new bone formation at the site of the hinge.

was seen in the patient with the S-shaped configuration at follow-up.

In group II-B both patients with the focal kyphotic type changed to the kyphotic type and there was deterioration of alignment in both patients with the kyphotic type at final follow-up (Table IV).

Degenerative slip. This was seen in 14 patients (16 intervertebral discs) before operation. At final follow-up, it had 
Table III. Mean ( \pm SD) preoperative and postoperative ROM (degrees) and CCI in the three groups

\begin{tabular}{|c|c|c|c|c|c|c|}
\hline & \multicolumn{3}{|l|}{ ROM } & \multicolumn{3}{|l|}{ CCI } \\
\hline & \multirow[b]{2}{*}{ Preop* } & \multicolumn{2}{|l|}{ Postop } & \multirow[b]{2}{*}{ Preop } & \multicolumn{2}{|l|}{ Postop } \\
\hline & & Short-term* & Long-term* & & Short-term & Long-term \\
\hline Group I-A & $41.1 \pm 12.1$ & $25.3 \pm 11.6$ & $27.7 \pm 9.7$ & $16.4 \pm 8.0$ & $10.5 \pm 8.4$ & $7.6 \pm 5.6$ \\
\hline Group I-B & $38.5 \pm 9.9$ & $25.4 \pm 7.8$ & $26.6 \pm 7.4$ & $-0.7 \pm 5.9$ & $-0.6 \pm 7.3$ & $-2.0 \pm 7.3$ \\
\hline Group II-B & $44.5 \pm 8.4$ & $26.3 \pm 9.1$ & $22.3 \pm 4.6$ & $-4.7 \pm 10.6 \dagger$ & $-15.6 \pm 16.5 \dagger$ & $-18.0 \pm 12.8 \dagger$ \\
\hline All & $40.7 \pm 11.1$ & $25.1 \pm 10.6$ & $25.4 \pm 8.7$ & $3.6 \pm 9.9$ & $-2.0 \pm 13.3$ & $-4.6 \pm 12.5$ \\
\hline
\end{tabular}

$* \mathrm{p}<0.01$ for short-term and long-term postoperative values compared with preoperative values

$\dagger p<0.05$ for short-term and long-term postoperative values compared with preoperative values

Table IV. Changes in alignment of the cervical spine

\begin{tabular}{|c|c|c|c|c|c|c|}
\hline & \multicolumn{6}{|c|}{ Long-term follow-up } \\
\hline & Lordotic & Straight & $\begin{array}{l}\text { Focal } \\
\text { kyphotic }\end{array}$ & Kyphotic & S-shaped & $\begin{array}{l}\text { Inverted } \\
\text { S-shaped }\end{array}$ \\
\hline \multicolumn{7}{|l|}{ Preoperative } \\
\hline Lordotic & 7 & 2 & & & & \\
\hline Straight & & 6 & 3 & & & \\
\hline Focal kyphotic & & & 5 & 3 & & \\
\hline Kyphotic & & & & $2 *$ & & \\
\hline S-shaped & & & & & $1 \dagger$ & \\
\hline Inverted S-shaped & & & & & & \\
\hline
\end{tabular}

Table V. Changes in degenerative slip in 16 discs

\begin{tabular}{lllll}
\hline & $\begin{array}{l}\text { Improvement or } \\
\text { disappearance }\end{array}$ & No change & Deterioration & $\begin{array}{l}\text { New } \\
\text { development }\end{array}$ \\
\hline $\mathrm{C} 2 / 3$ & $1^{*}$ & & & \\
$\mathrm{C} 3 / 4$ & $1^{*}$ & $3 \dagger$ & 2 & 1 \\
$\mathrm{C} 4 / 5$ & 3 & 2 & 2 & 1 \\
$\mathrm{C} 5 / 6$ & & 2 & & 1 \\
\hline
\end{tabular}

* one patient in whom posterolateral fusion was done at $\mathrm{C} 2 / 3$ and $\mathrm{C} 3 / 4$

$\dagger$ posterolateral fusion was performed in three patients, but further slip was seen

in two at C4/5 or C5/6 at final follow-up

progressed in two in group I-B and two in group II-B (four intervertebral discs). It was unchanged or improved in ten patients (12 intervertebral discs), four of whom had a posterolateral fusion (Fig. 2). Of these, two in group II-B had a further slip at a lower level with a change in alignment to the kyphotic type. Malalignment became worse in two patients in group I-B and four in group II-B, affecting the clinical symptoms (Table V).

The relationship between percentage improvement and alignment

Clinical results and preoperative alignment. The improvement was less and tended to deteriorate in the focal kyphotic, kyphotic and the S-shaped types of alignment.

The clinical results were good in the short term but only fair in the long term in the patients with the S-shaped and focal kyphotic types in group I-B and with focal kyphosis and kyphosis in group II-B. Poor long-term results were observed in one patient in group II-B with increased kypho- sis at the final follow-up (Table VI).

Clinical results and postoperative malalignment. In group I-B, deterioration of both alignment and clinical result was seen in one patient with an increased S-shaped type, and focal kyphosis changed to kyphosis in one of six patients at long-term follow-up.

In group II-B, a kyphotic change was observed in two patients with the focal kyphotic type, and deterioration of alignment was seen in two patients with the kyphotic type. In these four patients the results were worse at final followup. In three patients in group II-B, an unstable spondylolisthesis had been observed radiologically at the level of $\mathrm{C} 3 / \mathrm{C} 4$ or $\mathrm{C} 4 / \mathrm{C} 5$ before operation. In two of four patients in group II-B, a new slip was seen at C4/C5 or C5/C6 at the final follow-up, indicating a malalignment of the cervical spine. The clinical results were fair.

In 11 patients in whom malalignment had been observed before operation and at the final follow-up, the short- and 
Table VI. Radiological findings in patients with malalignment preoperatively and at follow-up

\begin{tabular}{|c|c|c|c|c|c|c|c|c|c|}
\hline \multirow[b]{2}{*}{ Case* $^{*}$} & \multirow[b]{2}{*}{$\begin{array}{l}\text { Age } \\
\text { (yr) }\end{array}$} & \multicolumn{3}{|l|}{ Preop } & \multicolumn{3}{|c|}{ Long-term follow-up } & \multicolumn{2}{|c|}{ Postop improvement (\%) } \\
\hline & & $\begin{array}{l}\text { Alignment } \\
\text { typet }\end{array}$ & CCI & Slip & $\begin{array}{l}\text { Alignment } \\
\text { type }\end{array}$ & CCI & Slip & Short-term & Long-term \\
\hline 1 & 52 & FK & -8.7 & & FK & -0.5 & & 80 & 80 \\
\hline 2 & 45 & FK & -10.5 & & FK & -9.0 & & 43 & 43 \\
\hline 3 & 70 & $S$ & 8.7 & $\mathrm{C} 3 / 4 / 5$ & $\mathbf{S}$ & 15.3 & $\mathrm{C} 4 / 5$ & 54 & 33 \\
\hline 4 & 67 & FK & 1.8 & & FK & 4.4 & & 43 & 43 \\
\hline 5 & 67 & FK & -2.3 & & FK & -5.0 & & 40 & 40 \\
\hline 6 & 59 & FK & -1.0 & $\mathrm{C} 3 / 4 / 5$ & $\mathbf{K}$ & -9.0 & $\mathrm{C} 4 / 5$ & 66 & 50 \\
\hline 7 & 74 & FK & -5.5 & $\mathrm{C} 3 / 4$ & FK & -7.5 & & 50 & 50 \\
\hline 8 & 58 & FK & -3.0 & $\mathrm{C} 3 / 4$ & $\mathbf{K}$ & -16.0 & $\mathrm{C} 3 / 4$ & 60 & 52 \\
\hline 9 & 51 & $\mathbf{K}$ & -22.4 & $\mathrm{C} 3 / 4 / 5$ & $\mathbf{K}$ & -37.0 & $\mathrm{C} 3 / 4$ & 46 & 18 \\
\hline 10 & 68 & $\mathbf{K}$ & -3.0 & C $3 / 4$ & $\mathbf{K}$ & -21.0 & $\mathrm{C} 4 / 5$ & 62 & 40 \\
\hline 11 & 59 & FK & 3.0 & C $3 / 4$ & $\mathbf{K}$ & -8.2 & C5/6 & 50 & 33 \\
\hline
\end{tabular}

* Cases 1 to 7, Group I-B; Cases 8 to 11, group II-B; Cases 10 and 11 had posterolateral fusion

† FK, focal kyphosis; K, kyphosis; S, S-shaped type

long-term improvements were $54 \%$ and $43.8 \%$, respectively (Table VI).

\section{DISCUSSION}

Until recently, cervical myelopathy due to cervical spondylosis, cervical stenosis and, in Japan in particular, ossification of the posterior longitudinal ligament has been treated surgically either by an anterior interbody fusion or posterior decompression.

The anterior procedure was used only in patients in whom the spinal canal had been severely narrowed at one or two levels. Patients with stenosis involving several segments usually had a posterior procedure with a wide laminectomy, after which there was a tendency for the development of deformity and instability of the spine with invasion of the canal by scar tissue, leading to return of the neural symptoms.

Since 1978, we have treated 136 patients with cervical myelopathy by canal-expansive laminoplasty. Postoperative follow-up by CT has shown no restenosis due to return of the opened lamina, and the canal expansion has been adequately sustained. Bone formation has been observed at the groove on the hinge side giving additional strength to the lamina. Thickening of the lamina has been observed on the dorsal side with no ossification of the gap in the laminae at the opened side which could narrow the spinal canal.

Posterolateral fusion was performed concomitantly in patients showing instability before operation. The crosssectional area of the spinal canal was increased to nearly normal by opening the separated lamina by $10 \mathrm{~mm}$.

Both static and dynamic factors are involved in the production of spinal-cord symptoms. Tominaga (1975) reported that the spinal cord could tolerate static compression to nearly $70 \%$ stenosis of the spinal canal as shown on lateral radiographs, but it will tolerate even greater static compression if movement of the vertebral column is restricted. Thus, the reduction of the range of motion to $60 \%$ after canal-expansive laminoplasty is an advantage since it leads to reduction of the dynamic factors. Canalexpansive laminoplasty may therefore simultaneously reduce both static and dynamic factors in spinal-cord compression.

Postoperative malalignment of the spine may occur after operation but is less frequent after canal-expansive laminoplasty than after conventional laminectomy (Oda, Hattori and Kawai 1986). In our study malalignment occurred or deteriorated in six patients who had had this operation, but deterioration was mild in two. In patients who showed $S$-shaped or kyphotic changes with slip before operation, the deformities worsened and the clinical results deteriorated. In such patients, canal-expansive laminoplasty with posterolateral fusion using bone grafts may assist in preventing late neurological deterioration. Of four patients who had had a posterolateral fusion, however, two showed further slip at a lower level at final follow-up.

Kurokawa et al (1986) and Hoshino, Kurokawa and Machida (1992) have recently reported that preservation of the ligamentum nuchae and reconstitution of the muscles attached at C2 will assist in preventing postoperative malalignment. Since 1990, they have used this method with encouraging results.

The authors wish to thank Professor K. Yamamoto, Tottori University, for his guidance and encouragement throughout this work.

No benefits in any form have been received or will be received from a commercial party related directly or indirectly to the subject of this article.

\section{REFERENCES}

Crandall H, Gregorius FK. Long-term follow-up of surgical treatment of cervical spondylotic myelopathy. Spine 1977;2:139-46.

Hirabayashi K, Miyakawa J, Satomi K, Maruyama T, Wakano K. Operative results and postoperative progression of ossification among patients with ossification of cervical posterior longitudinal ligament. Spine 1981;6:354-64.

Hoshino Y, Kurokawa T, Machida H. Long term results of the double door laminoplasty by longitudinal splitting of spinous process. Rinshou Seikeigeka 1992;27:257-62.

Ishihara A. Roentgenographic studies on the normal pattern of the cervical curvature. Nippon Seikeigeka Gakkai Zasshi 1968;42: 1033-44.

Itoh T, Tsuji H. Technical improvements and results of laminoplasty for compressive myelopathy in the cervical spine. Spine 1985;10: 729-36. 
Japanese Orthopedic Association. Scoring system for cervical myelopathy. J Jpn Orthop Asso 1994;68:490-503.

Kimura I, Oh-hama M, Shingu H. Cervical myelopathy treated by canal-expansive laminoplasty: computed tomographic and myelographic findings. J Bone Joint Surg [Am] 1984;66-A:914-20.

Kurokawa T, Nakamura K, Machida H. Cervical canal enlargement by split spinous process method. Bessatsu Seikei Geka 1986;9:30-2.

Nishituzi T. Roentgenographic studies on the cervical spine of patients with cervico-omo-brachial syndrome. Cent Jpn J Orthop Traumat 1963;6:890-917.
Oda Y, Hattori S, Kawai S. Deformity and prehension after laminectomy. Bessatsu Seikei Geka 1986;2:70-7.

Oyama M, Hattori S, Moriwaki N, et al. A new method of cervical laminectomy. Chubu Seisaishi 1973;16:792-4.

Tominaga S. Study of surgical treatment for cervical spondylotic myelopathy. Seikei Geka 1975;26:803-16.

Tsuji H. Laminoplasty for patients with compressive myelopathy due to so-called spinal canal stenosis in cervical and thoracic regions. Spine 1982;7:28-34. 